بررسى آَكاهى، نتحرش و عملكرد دختران مقطع سوم راهنمايى شهر ايلام

در زمينه سلامت بلوغ در سال تحصيلى 93 -1392

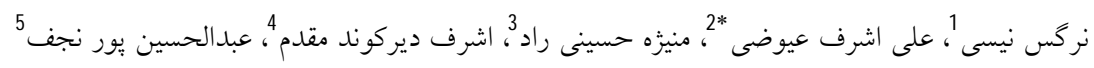

1) كميته تحقيقات دانشجويى، دلنشكاه علوم يزشكى إيلام، إيلام، إيران

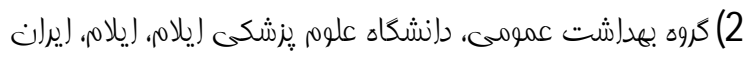

3) دانشكاه فرهنكيان ايلام، إيلام، إيرانغ

4) مركز تحقيقات بيشكيرى لز آسيب هاى اجتماعى 9 رولنى، دانشكاه علوم يزشكى إيلام، إيلام، إيران

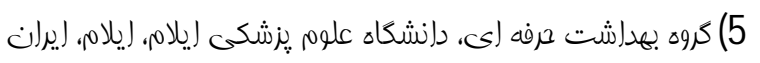

تاريخ بذيرش:94/9/14

تاريخ دريافت:94/2/22

مقدمه: نوجوانى يكى از مهم ترين و يرارزش ترين دوران هاى زندكى هر فرد محسوب مى شـود و بلـوغ بـارزترين تغييـر و

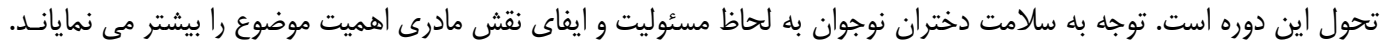

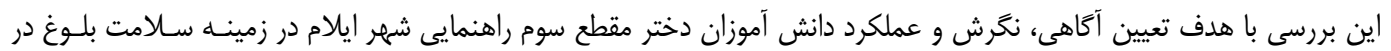

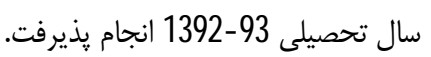

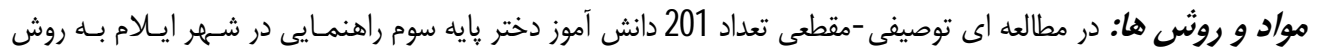

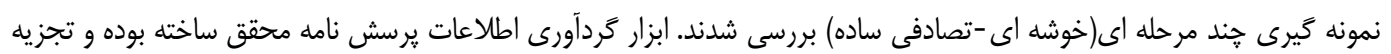

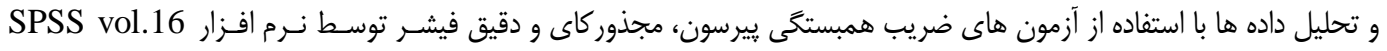
انجام شد.

يافته هايى بثزوهث: ميانگين سنى واحدهاى مورد يزوهش سطح آكاهى 6/2 درصد از مطالعه شوندكان در حد متوسط بود. از نظر نخرش

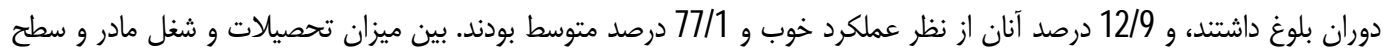

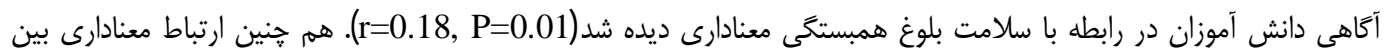

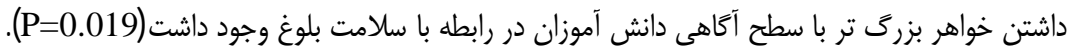

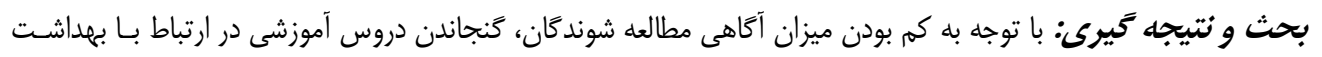

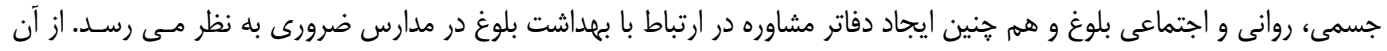

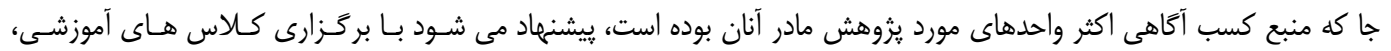
اطلاعات مادران در اين زمينه افزايش يابد.

وازه هاى كليدى: آَكاهى، نكَرش، عملكرد، بلوغ دختران

Email: ali.medilam@gmail.com * نو يسنده مسئول: گروه بهداشت عمومى، دانشخاه علوم يزشكى ايلام، ايلام، ايران 
علاقه مندى بيشتر به جنس مخالف، تمايل به آراستن

مقدمه

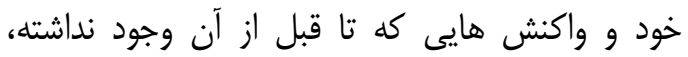

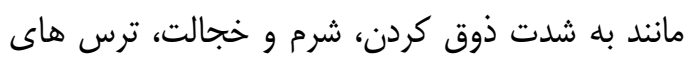

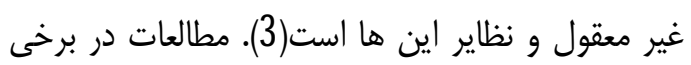

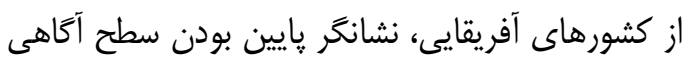

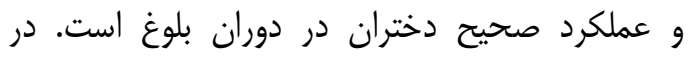

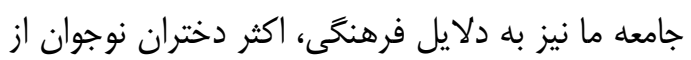

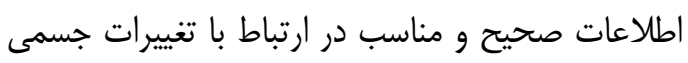

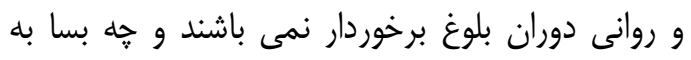
دليل كسب اطلاعات از منابع ناآكاه و غير موثق، در دراند زندگى خانوادگى خود دجار مشكلات جسمى و روانى إنى شوند(6).

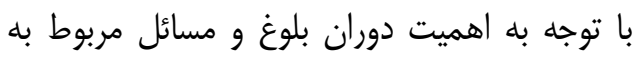

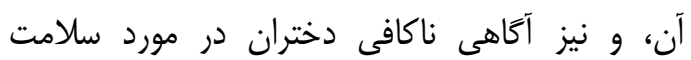

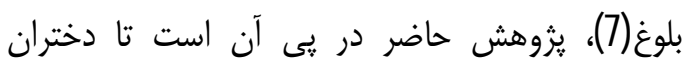
نوجوان مقطع سوم راهنمايى شهر ايلام را از نظر ميزان

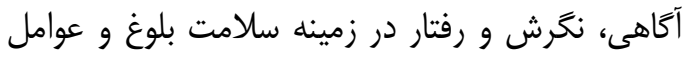

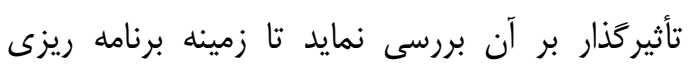

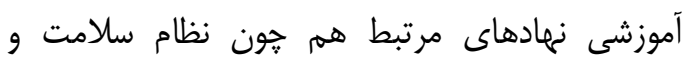

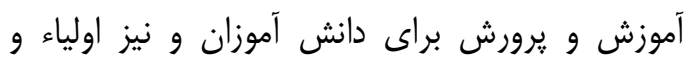
مربيان فراهم كردد. مواد و روش هان فر مر مرد

در مطالعه ايى توصيفى -تحليلى از نوع مقطعى،

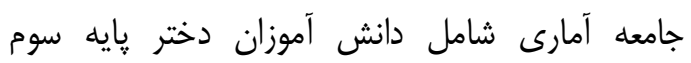

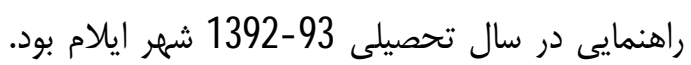
حجم نمونه بر اساس فرمول تعيين حجم نمونه 201

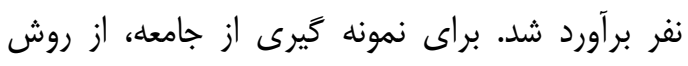
نمونه گيرى جند مرحله اى(خوشه اى -تصادفى ساده)

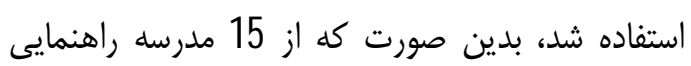

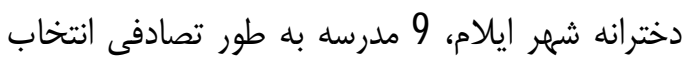

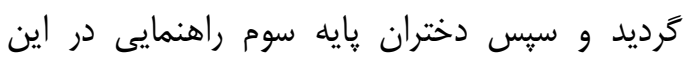

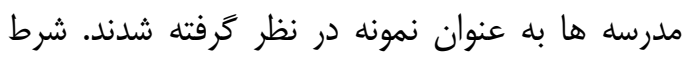
ورود واحدهاى يزوهش به مطالعه، گذراندن حداقل عاقل سه دوره عادت ماهيانه بود. ابزار گردآورى اطلاعات يرسش نامهانه ایى محقق ساخته و تنظيم شده در دو بخش بود. بخش اول بار بات 7

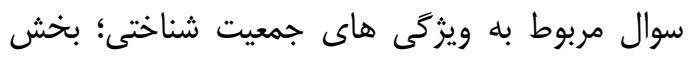

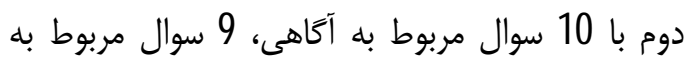

نوجوانى يكى از مهمم ترين برهه هاى زندكى است

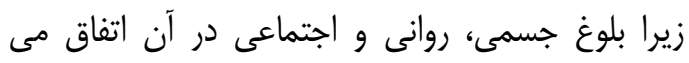
افتد(1). اين دوره كه با بلوغ جنسى شروع مى شى شود طى انى

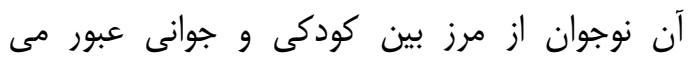
كند(2). بر اساس آمار سازمان جهانى بهراشت إن از هر

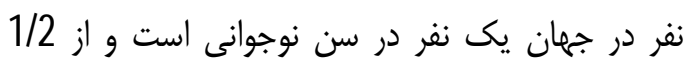

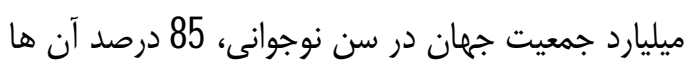

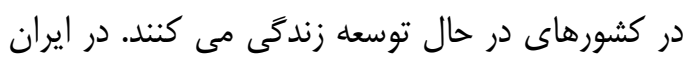

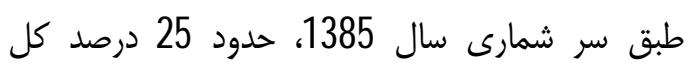

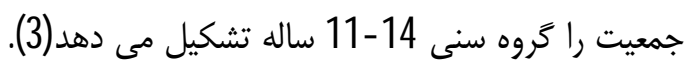

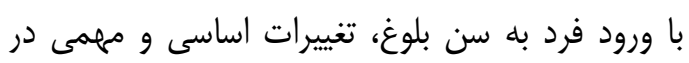

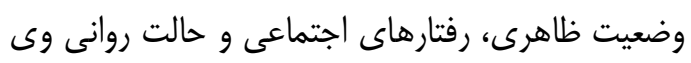

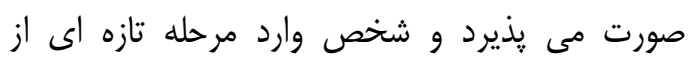

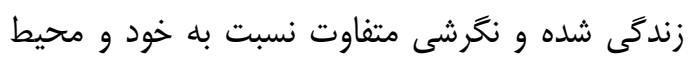

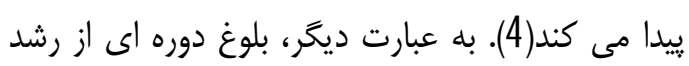

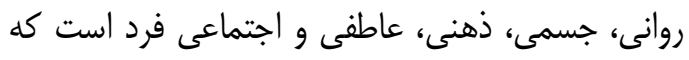

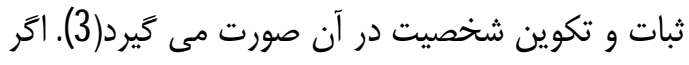
جه دوران بلوغ و مشكلات و كيفيت كذر از آن آن در هر دو جنس مهم است(3) ولى توجه به سلامت دختران

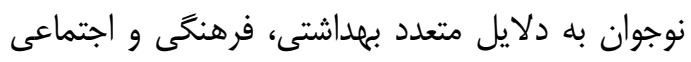
در مقايسه با يسران از اهميت بيشترى برخوردار است.

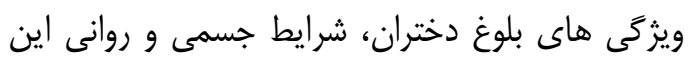

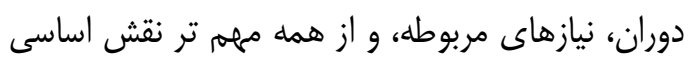
عوامل مزبور در بارورى و توليد مثل بر تمامى دورها

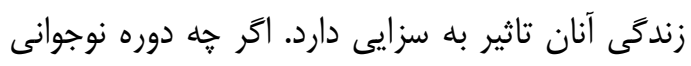

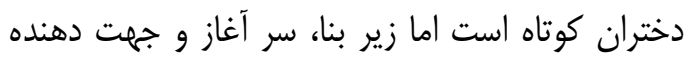

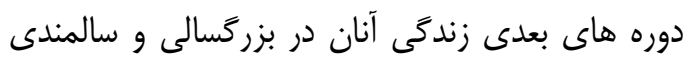
است. به علاوه تاثير مستقيمى بر خانواده و وكو كودكان

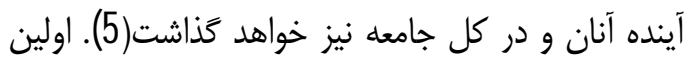

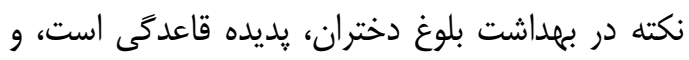

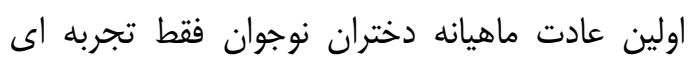

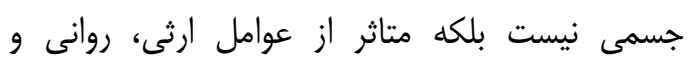

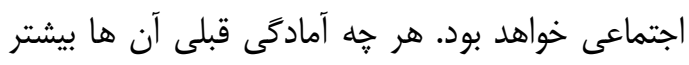
باشد، موضع مثبت ترى در قبال اين تغيير خواهند

داشت(3).

از ديخر ابعاد بلوغ دختران، مى توان به تاثير روانى

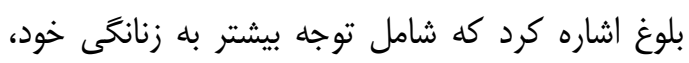


توصيف داده هاى كيفى نيز از جداول فراوانى استفاده شد. تجزيه و تحليل داده ها با استفاده از نرم افزار SPSS vol.16 انجام شد. سطح معنى دارى آمارى 005 لحاظ كَ ديد.

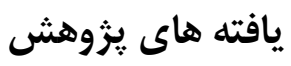
بررسى ويزگى هاى جمعيت هافئ شناختى واحدهاى

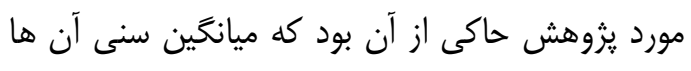

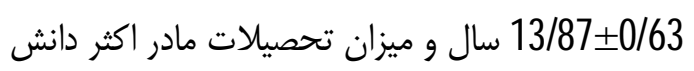

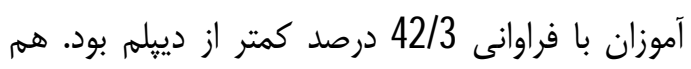
هنين شغل مادر در 81/1 درصد از موارد خانه دار بوده درد

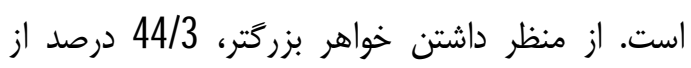

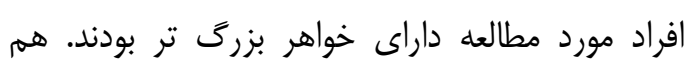

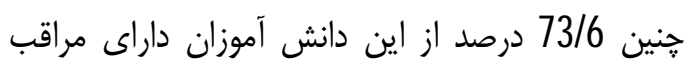

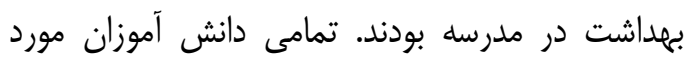

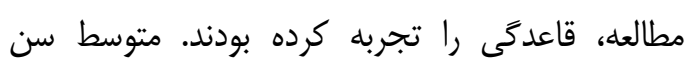
شروع قاعدگى(منارى)13 سالكى به دست آمدا

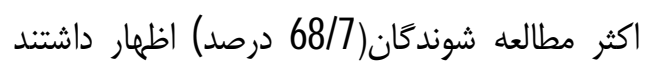

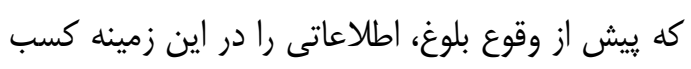

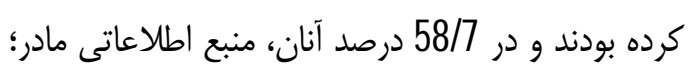

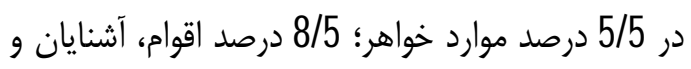

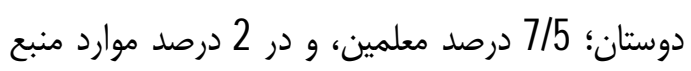
كسب آكاهى كتب، مجلات رسانه و واينترنت بوده است.

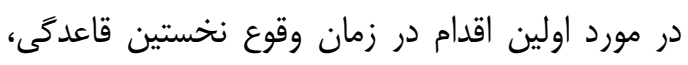
نتايج نشان داد كه 25/4 درصد از دانش آموزان دهار

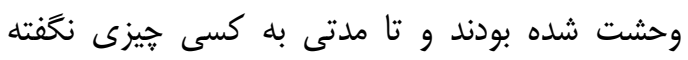

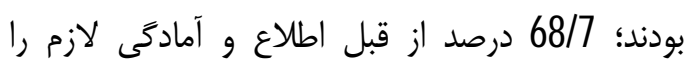

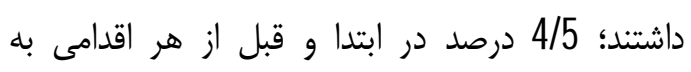

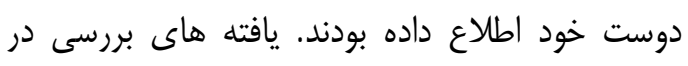

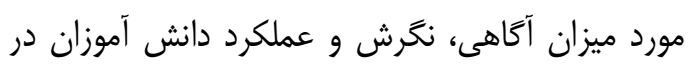

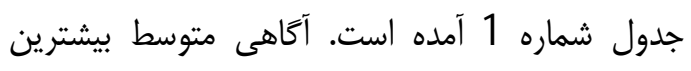

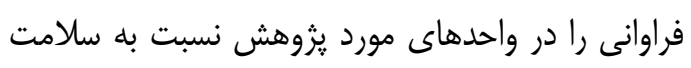

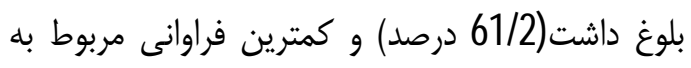
ميزان آكاهى خوب18/9 درصد) به دست آمد. 13/9 درصد از دانش آموزان نخرش مثبتى نسبت به دوابه دوران

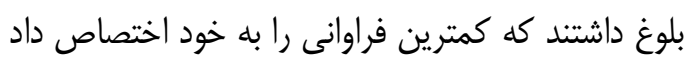

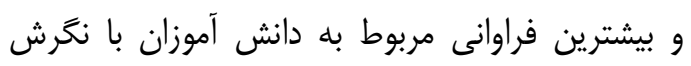

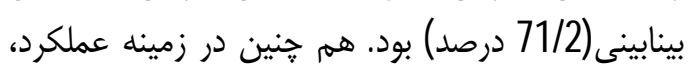

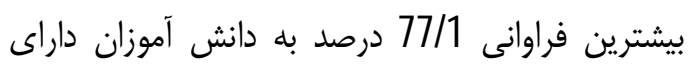

نخرش و13 سوال در رابطه با نحوه عملكرد واحدهاى

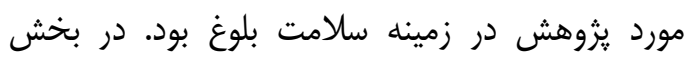

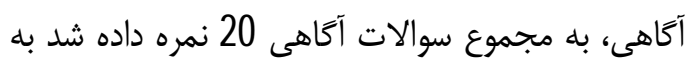

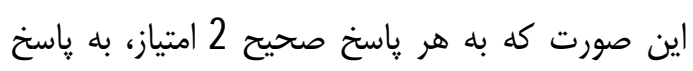

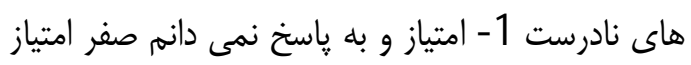

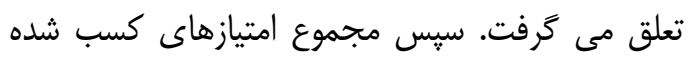
در اين قسمت محاسبه و ميزان آكاهى با كسب امتياز

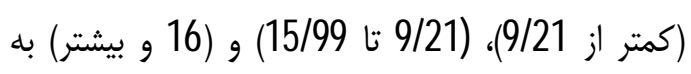

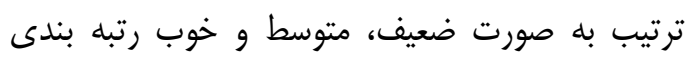

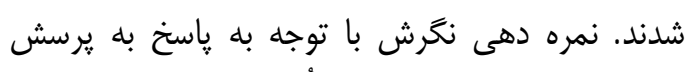

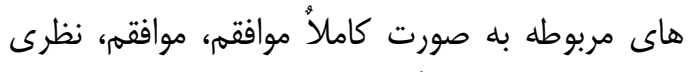

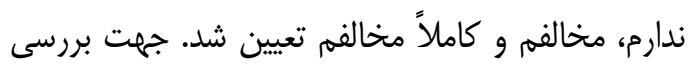

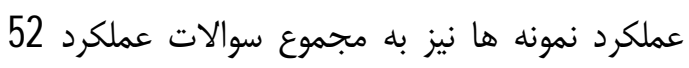
امتياز تعلق گرفت(هر ياسخ صحيح 4 امتياز). با توجه

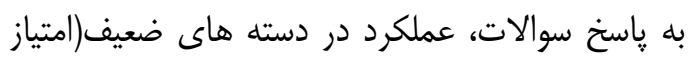

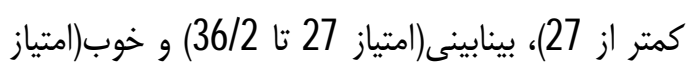
36/2 و بيشتر) طبقه بندى شد. براى تعيين روايى نيى

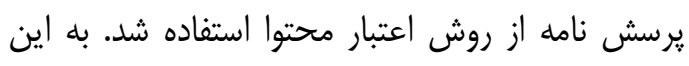

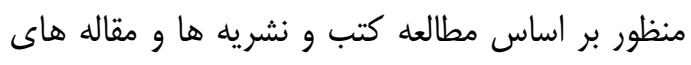

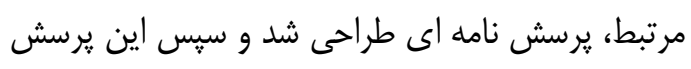

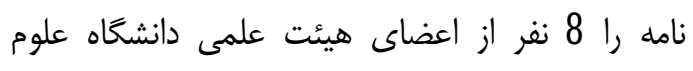

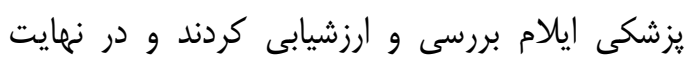

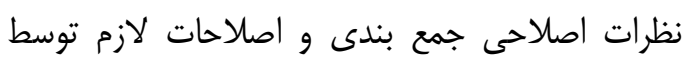

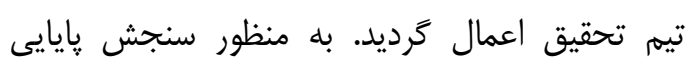

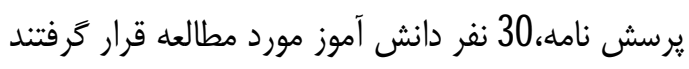

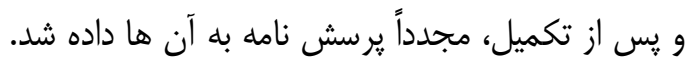
اين افراد در مطالعه اصلى وارد نشدند. البته ييش از بـاز توزيع يرسش نامه ها، در خصوص ملاحظات اخلاقى إنى

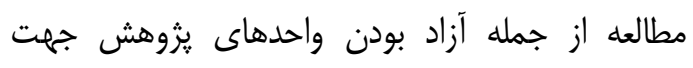

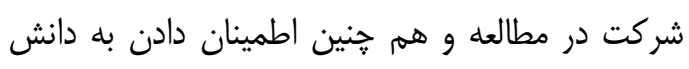

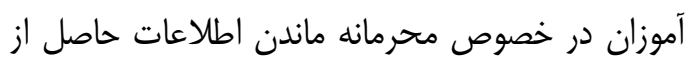

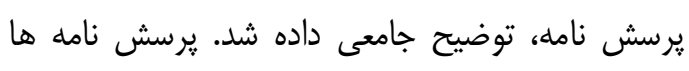
يس از كسب مجوز و معرفى نامه از اداره آموزش و

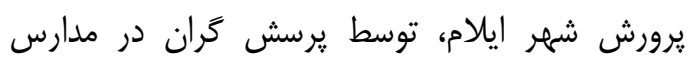
مربوطه تكميل شدند. داده هاى جمع آورى شده با استفاده از آزمون هاى

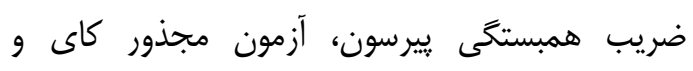

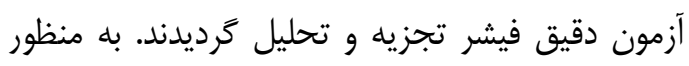


آموزان ديده نشد. در اين مطالعه ضريب همبستخى

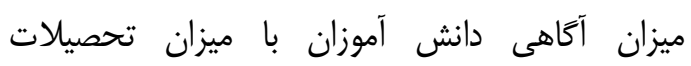

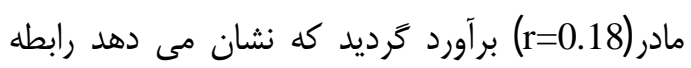

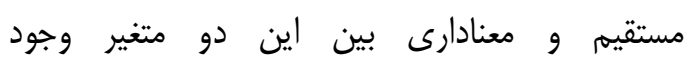

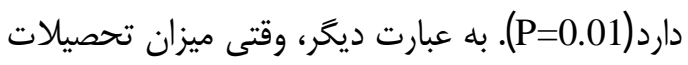

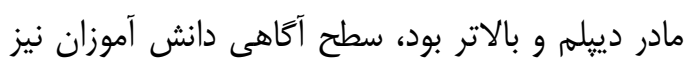
بيشتر بود.
عملكرد نسبتاً صحيح در زمينه سلامت بلوغ، و كمترين

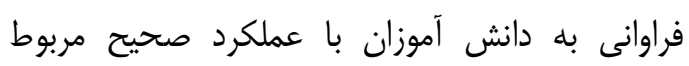
بود(12/9 درصد). در اين مطالعه، رابطه معنادارى بين داشتن خواهر

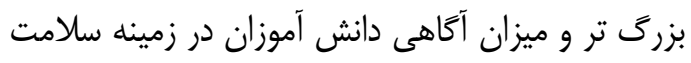

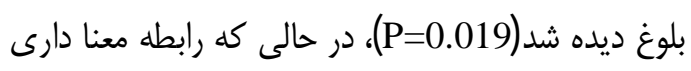

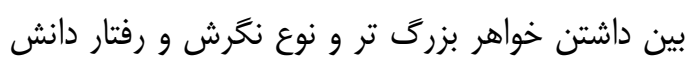

جدول شماره 1. توزيع فراوانى ميزان آكاهى، نوع نتَرش و نحوه عملكرد دانش آموزان دختر سوم راهنمايى در زمينه سلامت بلوغ

\begin{tabular}{|c|c|c|c|}
\hline عملكرد & نحرش & أكاهى & درجه متغير \\
\hline (درصد) فراوانى & (درصد) فراوانى & (درصد) فراوانى & \\
\hline $\bar{X}(1 \mathrm{C})$ & $3(11 / 9)$ & $4 \mathrm{C}(\mathrm{I} / \mathrm{C})$ & ضعيف \\
\hline $155(T / 1)$ & 14E (71/2) & $12=(凹 / 2)$ & متوسط \\
\hline $2 \in(1 / \mathrm{C})$ & $\chi(1 \equiv / \mathcal{C})$ & $\mathcal{B}(1 \varepsilon / \mathrm{C})$ & خوب \\
\hline $201(10)$ & $201(10)$ & $201(10)$ & جمع \\
\hline
\end{tabular}

ميزان سواد مادران نقش موثرى در توانايى انتقال دانش

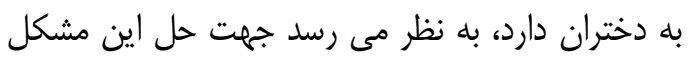

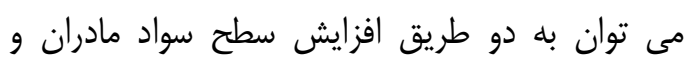

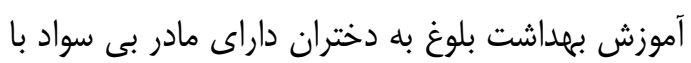

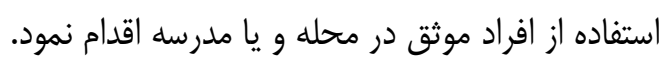

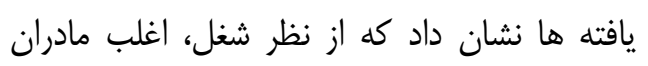

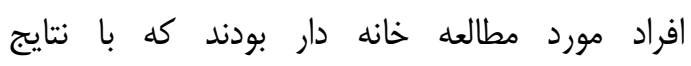
عبداللهى6) در استان مازندران و خاكبازان(4) در تهران

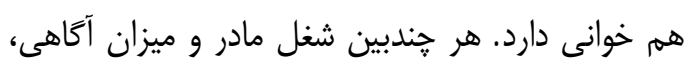

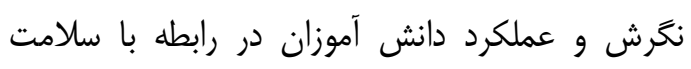
بلوغ رابطه معنادارى ديده نشد(P=0.6).

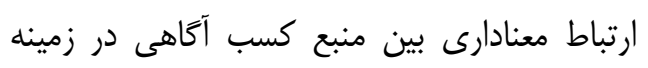

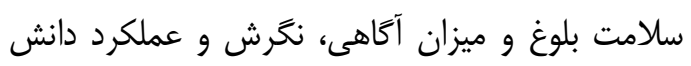

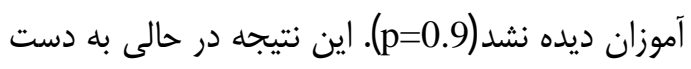

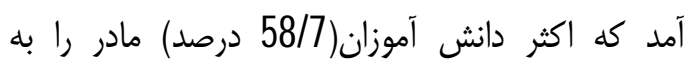

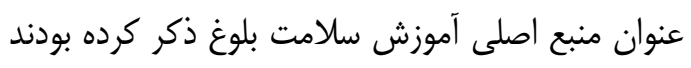

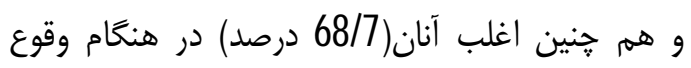

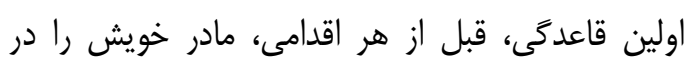

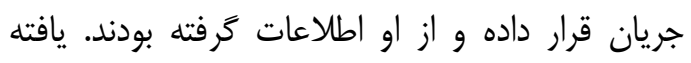

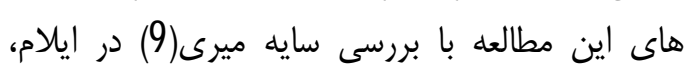

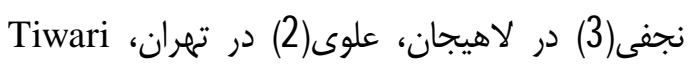
(16) در هند و Eswi
بحث و نتيجه كيرى

متوسط سن شروع قاعدىى در اين مطالعه 13 سالخى بود. از طرفى سايه ميرى(9) در ايلام

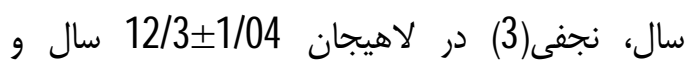
علوى(2) در تهران 12/5 سال و عبداللهیى(6) در استان مازندران 12/25 سال و Sharma (13) در نيال 12 سال و (14)Padmanabhan در امارات متحده عربى

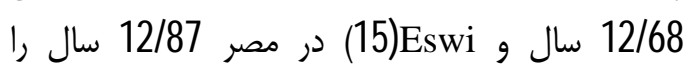
كزارش كرده اند. سن بلوغ متاثر از زنتيك، نزاد، اقليه و وضعيت تغذيه مى باشد كه اين امر كوناگونى يافته هاى مطالعات مختلف را تبيين مى نمايد. بررسى ميزان سواد مادران در اين مطالعه نشان داد ماد ماد كه اكثر مادران داراى تحصيلات كمتر از دييله بودند

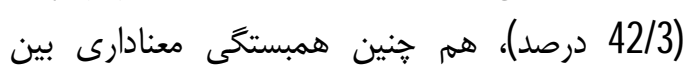

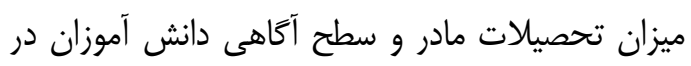
زمينه سلامت بلوغ ديده شد(r=0.18, P=0.01)، به تهيه عبارت ديخر، وقتى ميزان تحصيلات مادر دييلم و بالاتر

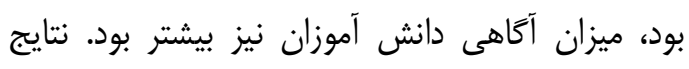
حاصل از اين مطالعه با يافته هاى علوى(2) در تهران اندان، نجفى(3) در لاهيجان و عبداللمى(6) در استان مازندران

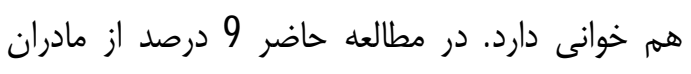

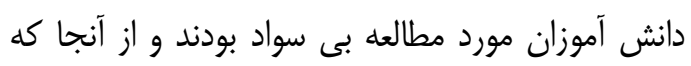


از دانش آموزان داراى عملكرد متوسط در زمينه هاى سلامت جسمانى و نيز روانى -اجتماعى بلوغ بودند كه

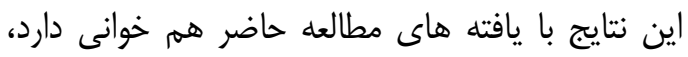

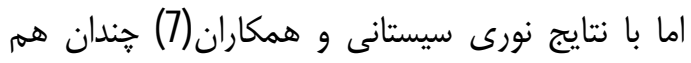

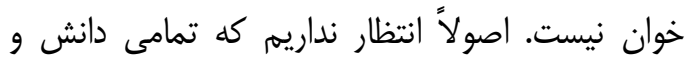

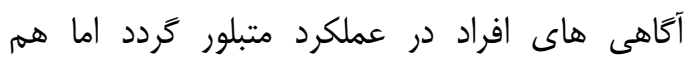

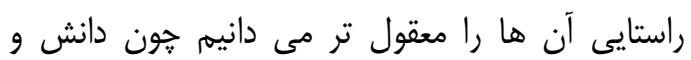

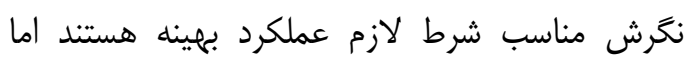
شرط كافى به شمار نمى روند. بيش از نيمى از شركت كنندكان در زمينه سلامت

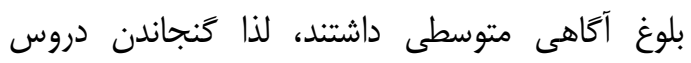

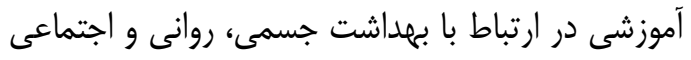

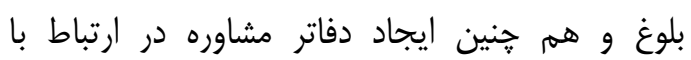

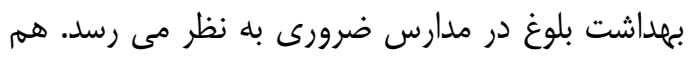

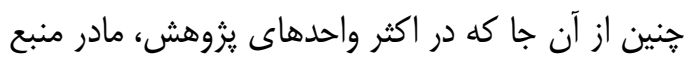

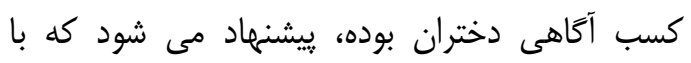
برگزارى جلسات آموزشى، آكاهى مادران در ائنى اين زمينه

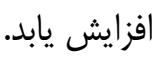

يرداختن به بهداشت بلوغ و آكَاهى بخشى در زمينه

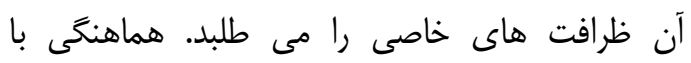

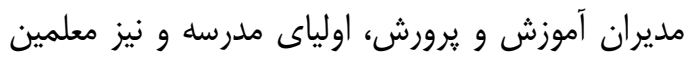

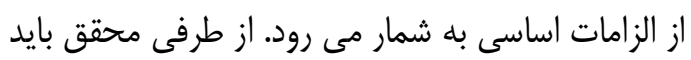

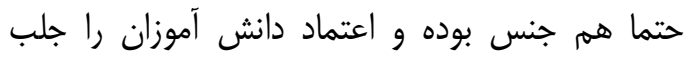
نمايد. با آن كه در كشورهاى غربى، محتواهاى مرتبط با بهداشت بلوغ و بارورى در كتاب هاى درسى آمده دهاه

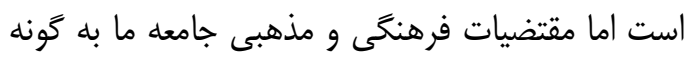

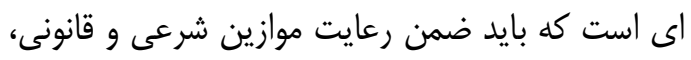

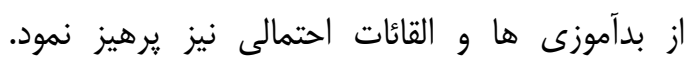

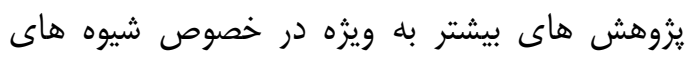

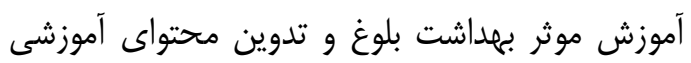

مناسب توصيه مى كردد. سباسگَزارى

از معاونت تحقيقات و فناورى دانشكاه علوم يزشكى

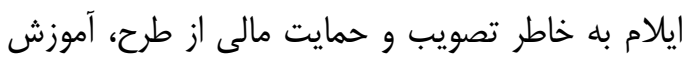

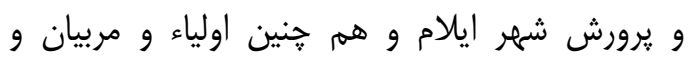
دانش آموزان مدارس مورد يزوهش، تشكر و قدردانى إنى

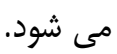

اين مطالعات اكثر دانش آموزان خانواده را به عنوان

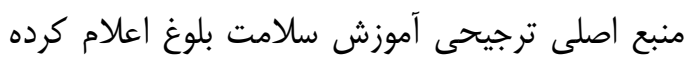

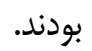
ميزان آكاهى اكثر دانش آموزان در زمينه سلامت

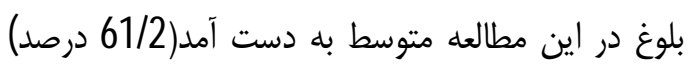

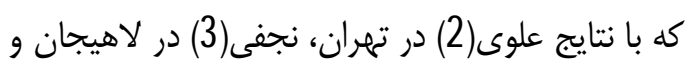

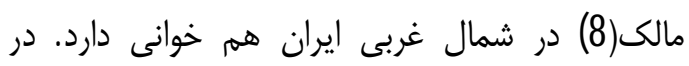
يثوهش هاى مزبور ميزان آكاهى دانش آموزان در مورد

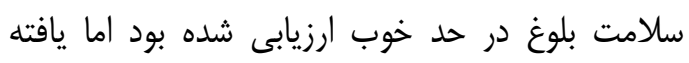

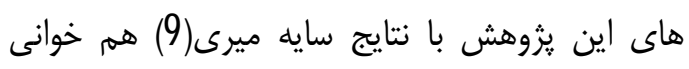

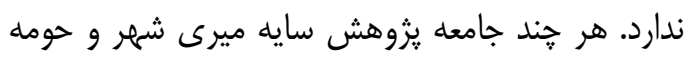
ايلام بوده ولى مطالعه حاضر فقط در شهر ايلام انجام

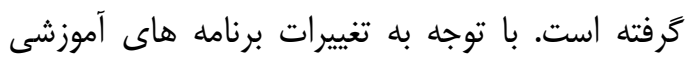

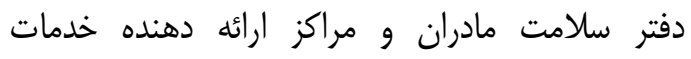
بهداشتى و درمانى طى اين مدت، تغيير در سطوح

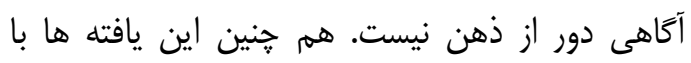

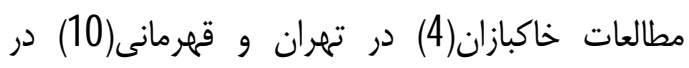
هابهار و نيز Gomes(11) در برزيل كه ميزان آكاهى دانش آموزان در مورد سلامت بلوغ را ضعيف كزارش

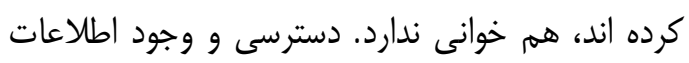

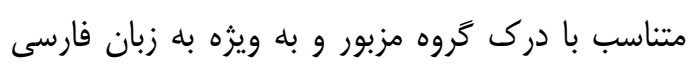
مى تواند تفاوت هاى مطالعات فوق را تبيين نمايد.

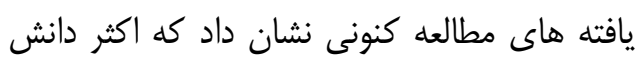
آموزان از نظر نخرش/71/2 درصد) در حد بينابينى قرار

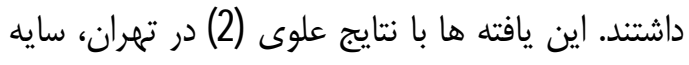
ميرى(9) در ايلام و هم هنين نجفى(3) در لاهيجان

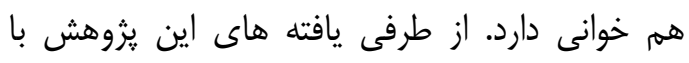

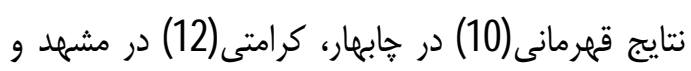

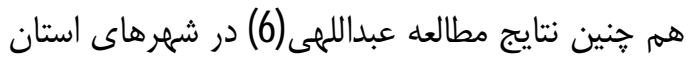
مازندران كه در آن دانش آموزان مورد مطالعه نخرش شعان

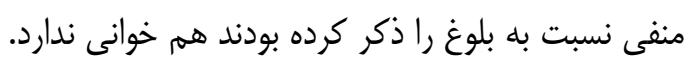

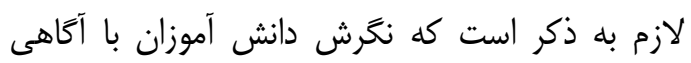

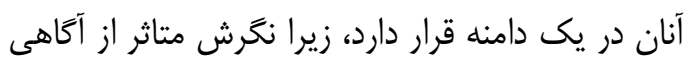

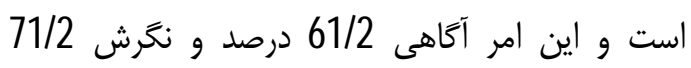
درصد را توجيه مى نمايد.

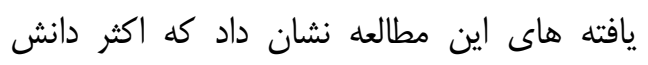

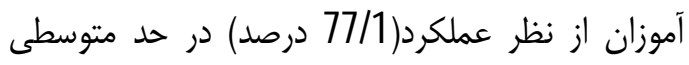

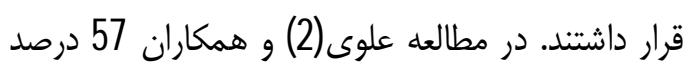


References

1.Moodi M, Zamanipour N, SharifzadehGh, Akbaribourang M, Salehi S. [Evaluating puberty health program effect on knowledge increase among female intermediate and high school students in Birjand]. J Birjand Uni Med Scie2006; 13:36-42.(Persian)

2. Alavi M, Poshneh K, Khosravi AA. [A survey of knowledge, attitudes and practices of third level students in Tehran in the field of adolescent health]. Payesh2008;8:59-65.(Persian)

3. Najafi F, Mozafari S, Mirzaee S. [Assessment of 3rdgrade junior school girl students, knowledge and attitude toward puberty age sanitation]. J Guilan Uni Med Scie2011;21:22-8.(Persian)

4. Khakbazan Z, Jamshidi F, Mehran A, Damghanian M. [Effects of lecture presentation and presenting educational packages on girlsknowledge about adolescence health]. J Nursmidwif Tehran Uni Med Scie 2008;14:41-8.(Persian)

5. Aghayousefi AR, Alipour A, Najaryhassanzadeh F. [Effectiveness of puberty and menstrual health education on gengral health of k9girls]. Psychol Res2009;1:105-18.(Persian)

6.Abdolahi F, Shabankhani B, Khani P. [Study of adolescent health education need of students in the province guides, 1382]. J MazandaranUni Med Scie 2004;14:5663.(Persian)

7. Noorisistani M, Merghatikhoi E. [The impact of peer-based education approaches on girls' physical practice of pubertal Health]. J Arak Uni Med Scie 2010;12:129-35.(Persian)

8. Malek, A, Shafieekandjani, AR, Safaiyan A, Abbasishokoohi, H. Sexual knowledge among high school students in
Northwestern Iran. J Pediatri2012, 22:1316.

9. Sayemiri K, Morvarid MJ. [A Survey and analysis of health needs in girls of guidance schools regarding puberty in Ilam and its suburbs]. J School Health 2006 5 :44-50.(Persian)

10.Ghahremani L, Heydarnia A, Babaie G, Nazary M. [Effects of puberty health education on health behavior of secondary school girl students in Chabahar city]. ISMJ 2008;11:61-8.(Persian)

11.Gomeswde A, Costa MC ,Sobrinho CL ,Bacelar EB. Adolescents knowledge about adolescence puberty and sexuality. $\mathbf{J}$ Pediatri2002;78 :301-8.

12. Karamati MR, Esfandiarimoghadam MR, Mahjoubeshratabadi H. [Effect of educational program of puberty health on Knowledge, attitude, and general health of teenagers]. Quart J New Thought Edu2009;5:35-50.(Persian)

13.Sharma M, Gupta S. Menstrual pattern and abnormalities in the high school girls of Dharan: across sectional study in two boarding schools. Nepal Med Coll J2003 ; 5:34-6.

14. Badrinath P, Ghazalaswad S, Parfitt D, Osman N. Cultural and ethnic barriers in conducting research factors influencing menarche in the United Arab Emirates. Saudi Med J 2004;25:1626-30.

15. Eswi A, Houaida H, Wafaa E. Menstrual attitude and knowledge among Egyptian female adolescents. J American Sci2012;8:555-65.

16.Tiwari H,Oza UN, Tiwari R. Knowledge attitudes and beliefs about menarche of adolescent girls in Anand district Gujarat. East Med Health J 2006; 12:428-33. 


\title{
Knowledge, Attitude and Performance of K-9 Girl Students of Ilam City toward Puberty Health in 2013-14
}

\author{
Naisi $N^{l}$, Aivazi $A^{2 *}$, Hoseinyrad $M^{3}$, Direkvandmoghadam $A^{4}$, Pournajaf $A^{5}$
}

\begin{abstract}
Introduction: Teenage is considered as a critical and invaluable period of any individual life, and puberty is the most important development of such age. The girls' health caring due to their future motherhood tasks is so important. The current study aimed at the assessment of knowledge, attitude and performance of $\mathrm{k}_{9}$ female students toward puberty health at Ilam, in 2013-14 academic year.
\end{abstract}

Material \& methods: In a cross-sectional study, 201 female $\mathrm{k}_{9}$ students were selected through multiple stage (cluster-simple random) sampling. A researcher-made questionnaire was used to collect data and the data were analyzed using $\chi^{2}$, Fisher exact, and Pearson's correlationtestsin SPSS-16 software.

Findingss: The age average of studied people was $13.87 \pm 0.63$ while menarche one was 13 years. The puberty awareness for $61.2 \%$, and attitude for $77.1 \%$ of attendants were moderate, however their performance in this regard for $12.9 \%$ and $71.1 \%$ were good, and moderate, respectively. The mother's education and job showed a statistically significant correlation to students puberty awareness $(\mathrm{r}=0.18, \mathrm{P}=0.01)$. Further, having an older sister showed statistically significant correlation to students knowledge on puberty health $(\mathrm{P}=0.019)$.

Discussion \& Conclusions: Due to low level of puberty knowledge among studied students, arrangement of educational and curricular programs on physical, mental, and social aspects of puberty, along with development of consultation offices at schools are recommended. Improvement of mothers' knowledge through educational programs will be useful, as knowledge source for the most of the respondents was their mother.

Key words: Knowledge, Attitude, Performance, Puberty

1. Student Research Committee, Ilam University of Medical Sciences, Ilam, Iran

2. Dept of Public Health, Faculty of Health, Ilam University of Medical Sciences, Ilam, Iran

3. Ilam Farhangian University, Ilam, Iran

4. Psychosocial Injuries Research Center, Ilam University of Medical Sciences, Ilam, Iran

5. Dept of Occupational Health, Faculty of Health, Ilam University of Medical Sciences, Ilam, Iran

*Corresponding Author, email: ali.medilam@gmail.com

\section{Scientific Journal of Ilam University of Medical Sciences}

